\title{
Construction and Design Parameters of the Reducer-Variator
}

\author{
Ovtov Vladimir Alexandrovich \\ Department of Mechanization of technological processes in the Agro-Industrial Complex, Penza State Agrarian University, Penza, \\ 440014, Russia
}

Received 15 May 2021; Accepted 19 July 2021

\begin{abstract}
One of the directions of the vegetable growing industry is the cultivation of onions, which occupies a significant place in the total content of vegetable production, however, the current production structure in Russia does not fully ensure the consumption of domestic products by the population of the country all year round. Therefore, increasing their productivity is relevant. The article presents the substantiation of the design parameters of the onion planter variator gearbox, which could ensure the planting of the onion set with the bottom down with the seeding rate. The construction of the designed three-dimensional model of the reducer-variator is presented and its operation is described.
\end{abstract}

Keywords: onion, sowing, reducer-variator, modeling, shaft.

\section{Introduction}

The sown area of onions in the Russian Federation is about 30-40 thousand hectares. Onion cultivation is mainly concentrated in the Middle Volga region and southern regions of the country. These highly mentioned regions could provide appropriate soil and climatic conditions that are confortable for the production of onions. In order to successfully promote its production in a market economy, any manufacturer is obliged to provide customers with products of high quality and in the planned quantity, leaving with it at the moment on the market. And this is impossible without applying up-todate equipment. The sustainable development of modern technology makes it possible to obtain profitable onion yields during the growing season.

Planting onion sets is fundamental in the implementation of the onion technological process [1-3]. The most widespread are reel-to-reel, fork-type, spoon-type or bandsowing seeders and planters.

The process of sowing onions depends on the speed of the planting device, its working width, the cost of planting, as well as the time for auxiliary technological operations [2-5]. For band-sowing onion sets, the onions are placed in a row at a distance of $8 \ldots 10 \mathrm{~cm}$ for varieties that give one onion, and for varieties that give three or more onions in a nest, the distance should be $10 \ldots 15 \mathrm{~cm} \mathrm{[3-7].}$

The band-sowing method provides for the piece-by-piece supply of onion sets by a sowing device, while the planting rate is regulated using replaceable sprockets [6-9]. The following onion planters such as MPLS-4, SL-1, BUL-2, Krukowiak, Zocapi brands are equipped with chain reducers, where it takes from 20 to 30 minutes to replace the sprockets to change the seeding rate.

The disadvantages of this regulation of the seeding rate could be attributed to the increase in labor costs for replacing the sprockets during the transition of sowing onion sets of different fractions. Hence, an increase in the productivity of

*E-mail address: 0vtovVlad@mail.ru

ISSN: 1791-2377 @ 2021 School of Science, IHU. All rights reserved.

doi:10.25103/jestr.143.22 the planting unit when sowing onion sets is possible due to the implementation of technical solutions aimed at reducing the time spent on an auxiliary technological operation to replace the gear sprockets to change the planting rate.

\section{Materials and methods}

The stepless reducer-variator allows to abandon the old method of adjusting the seeding rate by reinstalling replaceable sprockets in the seeding unitscal. To ensure the necessary technological requirements for the operation of the onion planter, it is possible to upgrade it with a stepless impulse reducer with a wide range of gear ratios.

Currently known lever variators (Patent RU No. 2467227 publ. November 20, 2012, bull. No. 32; RF Patent No. 174717, publ. 10/30/2017, bull. No. 31) for smoothly changing the range of gear ratios, and therefore the rotational speed output shaft. The disadvantages of the devices include the complication of the kinematics of the drive mechanisms when using these by the variator, low reliability due to the large number of moving parts, as well as the complexity of manufacturing.

Several devices for stepless regulation of the gear ratio, which ensures smooth regulation of the seeding rate has been developed before (Patent RU No. 2679707, publ. 12.02.2019, bull. No. 5; RF patent No. 191524, publ. 12.08.2019, bull. No. 23). The disadvantages of the devices are the metal consumption, as well as the cyclic rotation of the shaft of the sowing device, due to the three cams; and the appearance of dead spots at low speeds. The proposed variator (Patent RU No. 2678179, publ. 01/23/2019, bull. No. 3) allows stepless adjustment of the driven shaft speed, but its disadvantages include the difficulty of selecting the working surface of the cams, the operation of which would affect the smoothness of the seeding rate regulation seeds.

Figure 1 shows a three-dimensional model of a stepless reducer-variator (Patent2744376 RF.Publ. 09.03.21, Bul. No. 7) developed at Penza State Agrarian University to drive the shaft of the seeding apparatus of the onion planter. The 
stepless reducer-variator for sowing onions consists of a housing 1, bearings 2 mounted on the driven shaft 3 , overrunning clutches 4 , pushers 5 with rollers 6 , pivotally connected to overrunning clutches 4 , tension springs 7 , guide 8 with adjusting lever 9 and four cams 10 fixed to the drive shaft 11.

The proposed stepless reducer-variator for sowing onions works as follows. When the drive shaft 11 rotates, the cams 10 act on the rollers 6 of the pushers 5 , pivotally connected to the overrunning clutches 4 , while the pushers 5 with the overrunning clutches 4 perform reciprocating movements using the action of the tension springs 7 of one of the rollers 6 with the cam 10, and the other roller 6 - with the track of the guide 8 . The tension springs 7 return the pushers 5 to their original position. Adjustment of the speed of rotation of the driven shaft 3 is carried out by the adjusting lever 9 of the angle of rotation of the guide 8 , which changes the stroke of the pushers 5 per unit of time.

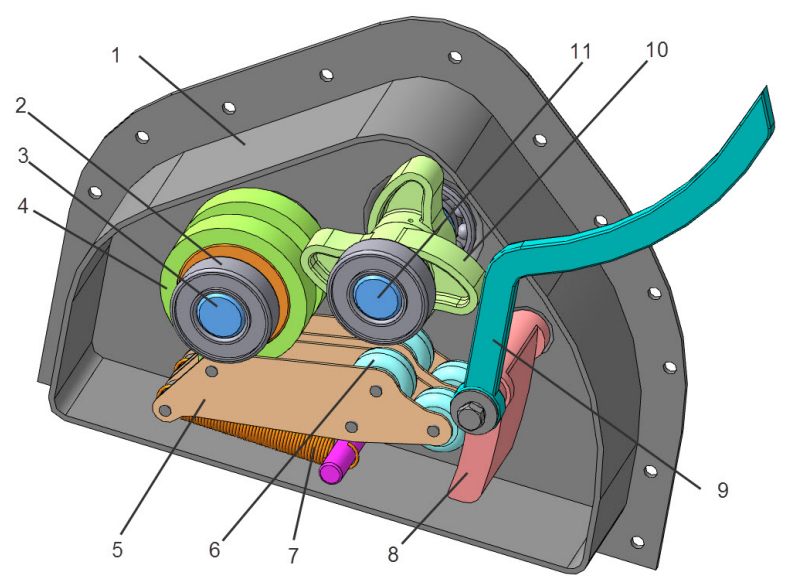

Fig. 1 Stepless reducer-variator

\section{Results and Discussion}

The cam mechanism is quite versatile. The cam mechanism is a device consisting of a cam rotating around an axis and a moving pusher in a certain way.

The reciprocating movement of the pusher arms pivotally connected to the overrunning clutches could be realized using a cam mechanism. Rotating motion simulates a change in some argument, and the pusher's stroke requires a pattern as a function of the argument. This pattern indicates the numerical between the radius of the dependence cam profile and angle of rotation $\varphi$, at which the specified stroke of the pusher is provided based on the operating conditions of the pulse reducer.

Figure 2 shows that the intensity of the pusher stroke does not determine the angle of rise of the profile $\alpha_{x}$ at point $A$, and the corner $\alpha$, made perpendicular to the Ox axis and a tangent curve equidistant to the cam profile curve passing through the center of tip $A_{1}$.

Since the dimensions of the tip (radius $R$ of the roller) are smaller than the dimensions of the cam, therefore the values $a$ and $\rho_{X}$ of the same order, therefore, inaccuracies made according to $\rho_{X}$ and installation $\varphi_{X}$ without a noticeable error can be attributed to the radii $\rho$ and corners $\varphi$. The cam profile itself can be obtained by constructing the envelope $\mathrm{AB}$ to the surroundings with radius $R$, the centers which are at the equidistant $A_{l} B_{l}$. It is possible not to search for the $\mathrm{AB}$ envelope of the true profile, to restrict ourselves to the found coordinates $\rho$ and $\varphi$ equidistant $A_{l} B_{l}$, if the tool for manufacturing and control of the cam surface is made of the same radius $R$ as the pusher tip (Fig. 2).

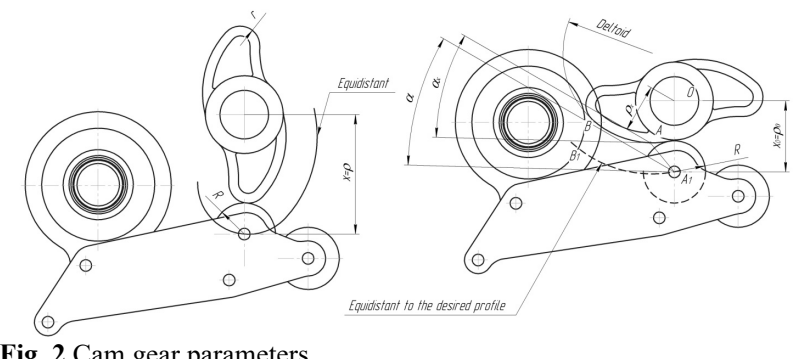

Fig. 2 Cam gear parameters

The working profile of the cam of the designed stepless reducer-variator when approaching at an angle $\varphi_{s}$ (Fig. 3) is made by an algebraic curve - a deltoid, and at this radius of rounding of a deltoid with a profile of the distant position of the cam at an angle $\varphi_{d}$ is $r=(0.60 \ldots 0.63) R$, where $R$ is the radius of the pusher roller.

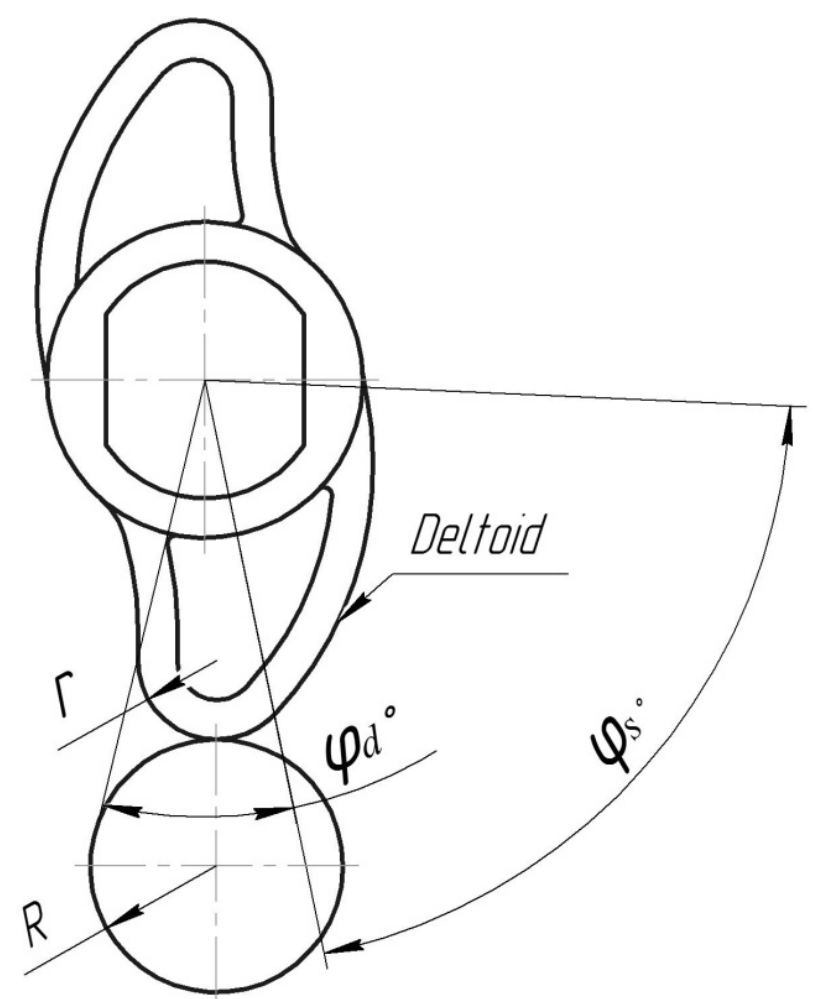

Fig. 3 Cam profile of the pulse reducer formula

The gear ratio of the pulse reducer is determined by the $i=\frac{n_{1}}{n_{2}}$

where $\mathrm{n}_{l}$ is the rotational speed of the drive shaft, $\min ^{-1} ; \mathrm{n}_{2}$ frequency of rotation of the driven shaft, $\min ^{-1}$. In this case, the range of changes in the gear ratio of the gearbox varies from 21.95 to 2.48 when the lever is indicated on a scale division from 5 to 100 .

Since the cams provide a cyclically constant action on the pushers, the change in the angle of rotation of the driven shaft 
3 (Fig. 1), which means that the gear ratio of the gearbox is performed by adjusting the position of the guide 8 .

When using a reducer-variator to drive seeder and planters, the seeding rate of planting material, which is set before starting work, would depend on the gear ratio.

The guide is adjusted by a rotary lever 9 , which is installed in the housing 1 with axial rotation, on which 8 is rigidly fixed. The second end of the rotary lever 9 is brought out of the housing 1, which points to a scale with divisions.

In the "position zero" of the adjustment mechanism, the guide 8 takes its initial vertical position, while the pusher levers also perform a simple swinging motion with the overrunning clutch. In this case, the overrunning clutch yoke 4 stands motionless, without driving the driven shaft 3 . When the control mechanism is moved to an intermediate position, the rollers 6 of the pushers 5 roll around the surfaces of the cams 10 mated with them, as well as in the "position zero", in this position the position guide 8 , which rotates at a certain angle relative to the axis of rotation. As a result, the pusher 5 is forced to perform a complex reciprocating motion, while turning the freewheel clip, and with it the shaft 3 , by a certain angle $\beta$. When increasing the seeding rate, increase the angle of rotation of the guide 8 , which leads to an increase in the angle $\beta$ of rotation of the freewheel cage.

The presented mathematical model is adequately represented by the dependence of the gear ratio of the reducervariator on the number of divisions of the adjustment scale $y$ $=f(x)$ (correlation index $\mathrm{R}=0.9999)$.

$$
\begin{gathered}
y=-7,778 \cdot 10^{-9} x^{5}+3,175 \cdot 10^{-6} x^{4}--4,931 \cdot 10^{-3} \\
\cdot x^{3}+3,71 \cdot 10^{-2} \cdot x^{2}-
\end{gathered}
$$

$$
-1,435 \cdot x+28,28
$$

where $y$ is the gear ratio of the reducer-variator, $x$ is a scale division.

Thus, the dependence of the gear ratio, and, consequently, the rotational speed of the sowing device shaft on the position of the position of the control lever, could be used to compile a table of seeding rates for onion sets, and the change in the seeding rate depending on the fraction could be $2 \ldots 3$ minutes.

\section{Conclusions}

The designed stepless reducer-variator for sowing onions allows smooth regulation of the planting rate of onion sets in various fractions, regardless of the speed of the unit. The current model describes the dependence of the gear ratio of the reducer-variator on the number of divisions in the adjustment scale, allows to set a predetermined rate of costs for auxiliary assembly and disassembly operations for replacing replaceable sprockets in the traditional method, which could lead to a decrease in manual labor costs and an increase in productivity when planting onions.

This is an Open Access article distributed under the terms of the Creative Commons Attribution License.

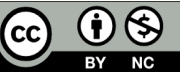

\section{References}

1. Aksenov A.G, Izmaaylov A.Yu., Dorokhov A.S., Sibirev A.V. Onion bulbs orientation during aligned planting of seed-onion using vibration-pneumatic planting device. INMATEH - Agricultural Engineering, 2, 2018, pp. 63

2. Sibirev A.V., Aksenov A.G., Dorokhov A.S. Results of laboratory investigations of soil screening ability of a chain digger with asymmetric vibrator arrangement. INMATEH - Agricultural Engineering 1, 2019, pp. 9

3. Laryushin N.P., Pivovarov V.F., Kukharev O.N., Vershinin Yu.A. Complex of machines for onion production using resource-saving technologies. Vegetables of Russia, 6, 2019, pp. 141

4. Aksenov A.G., Emelianov P.A., Ovtov V.A., Sibirev A.V. Reel-fork planting apparatus. Agricultural machines and technologies, 5, 2015, pp. 20

5. Hevko R.B., Tkachenko I.G, Synii S.V. Development of design and investigation of operation processes of small-scale root crop and potato harvesters. INMATEH - Agricultural Engineering, 49 (2), 2016, pp. 53

6. Sibirev A.V., Aksenov A.G., Mosyakov M.A. Experimental laboratory research of separation Intensity of onion set heaps on rod elevator. Journal of Engineering and Applied Sciences, 23, 2018, pp. 10086

7. Ovtov V.A., Chirkova N.S., Gudin V.M. Auger orienting device for planting sugar beet root crops. IOP Conf. Ser.: Earth Environ. Sci., 659, 2021, pp. 012017

8. Aksenov A G, Sibirev A V, Emelianov P.A. Oriented bulbs planting with forked-roller planting apparatus. Vestnik of Mordovia University, 1, 2018, pp. 24

9. Farhadi R., Sakenian N., Azizi P. Design and construction of rotary potato grader. Bulgarian Journal of Agricultural Science, 2, 2012, pp. 304 